\title{
Antimicrobial activities of different solvent extracted sample of Hippophae rhamnoides L. (Sea Buckthorn)
}

Saima $^{1}$, Wisal Muhammad Khan ${ }^{1}$, Arshad Iqbal ${ }^{1}$, Hoor Shumail ${ }^{2}$, Shah Khalid $^{1 *}$, Naveed Akhtar ${ }^{1}$, Nasreen Ghaffar ${ }^{3}$ and Syed Inzimam Ul Haq ${ }^{1}$

1. Department of Botany, Islamia College Peshawar, KPK, Pakistan

2. Department of Microbiology, Women University Mardan, KPK, Pakistan

3. Directorate of Higher Studies, Islamia College Peshawar, Pakistan

*Corresponding author's email: shahkhalid@icp.edu.pk

Citation

Saima, Wisal Muhammad Khan, Arshad Iqbal, Hoor Shumail, Shah Khalid, Naveed Akhtar, Nasreen Ghaffar and Syed Inzimam Ul Haq. Antimicrobial activities of different solvent extracted sample of Hippophae rhamnoides L. (Sea Buckthorn). Pure and Applied Biology. Vol. 11, Issue 1, pp259-270.

http://dx.doi.org/10.19045/bspab.2022.110028

\begin{tabular}{llll}
\hline \hline Received: 18/03/2021 & Revised: 20/05/2021 & Accepted: 22/05/2021 & Online First: 15/06/2021 \\
\hline \hline
\end{tabular}

\section{Abstract}

The current study was aimed to investigate the antibacterial and antifungal activities of various extracted samples of fruit of Hippophae rhamnoides L. The antibacterial and antifungal activities of various solvent extracted samples (crude ethanolic, chloroform, butanolic, ethyl acetate and aqueous) of Hippophae rhamnoides L. fruit were investigated through Agar Well Diffusion Method against five bacterial strain (two were Gram positive and three were Gram negative) and three fungal strains. The data was taken in comparison with reference drugs like azithromycin and clotrimazole. Three different concentrations i.e., $1 \mathrm{mg} / \mathrm{well}, 2 \mathrm{mg} / \mathrm{well}$ and $3 \mathrm{mg} / \mathrm{well}$ each of five extracts were subjected against five pathogenic bacterial isolates i.e. Salmonella typhi, Staphylococcus aureus, Escherichia coli, Bacillus subtilis and Pseudomonas aeruginosa and three fungal isolates i.e. Curvulria, Alternaria and Rhizopus spp. The antibacterial effects of crude ethanolic and aqueous extracts were highest, followed by butanol, chloroform and ethyl acetate fraction respectively. The crude aqueous and ethanolic extracts showed highest inhibitory activity against Salmonella typhi $(66.87 \pm 1.15 \%, 66.9 \pm 0.577 \%)$, Staphylococcus aureus $(97.5 \pm 1 \%$, $88.5 \pm 0.577 \%)$, Escherichia coli $(80.58 \pm 0.577 \%, 69.70 \pm 1.52 \%)$, Bacillus subtilis $(93.54 \pm 3.60 \%$, $77.41 \pm 1.73 \%)$ and Pseudomonas aeruginosa $(95.67 \pm 1.15 \%, 91.34 \pm 2.30 \%)$ at concentration $3 \mathrm{mg} /$ well. Similarly, maximum antifungal activity was shown by ethanolic extract i.e. $96.37 \pm 0.577 \%$ zone of inhibition against Curvularia sp. $79.28 \pm 1.52 \%$ against Alternaria and $89 \pm 1 \%$ against Rhizopus sp. at concentration of $3 \mathrm{mg} /$ well.

Keywords: Antibacterial; Antifungal; Hippophae rhamnoides L.; Sea Buckthorn

\section{Introduction}

For decades, bacterial and fungal infections have been a major problem causing various diseases in humans, plants, animals and spoilage of food products leading to the losses in the crop productivity and major health problems. The use of higher plants and preparation made from them to treat various infections is an old age practice in many parts of the world $[1,2]$. Therefore, antimicrobial 
properties of plants have revived as a consequence of present diseases associated with use of antibiotics. Moreover, the medicinal plants have been investigated to be biologically active because of occurrence of many compounds with antimicrobial, antioxidant, allopathic and bio-regulatory properties [2-4]. Hippophae rhamnoides L. belongs to the family Elaeganceae. It is a shrub and unisexual plant commonly recognized as sea-buckthorn. It is widely distributed throughout Europe and Asia. Three species were reported in Europe, Central Asia and the Himalayas and one species present in Pakistan $[5,6]$. According to the flora of Pakistan, Hippophae rhamnoides L. have oblong, shiny seed with scanty endosperm, female solitary flowers, pedicellate, perianth, and tubular male flowers in axillary clusters, having four stamens. Fruit are utricle, deciduous shrubs or small trees. Leaves are linear-lanceolate, petals 2, opposite, longer than the perianth tube $[7,8]$. Sea buckthorn plants, particularly berries and leaves are considered as an excellent source of important vital compounds like flavonoids, carotenoids, sterols and vitamins ( $\mathrm{C}, \mathrm{A}, \mathrm{K}$ and $\mathrm{E})$, which contains maximum nutritional and medicinal properties [9]. Elemental analysis of sea buckthorn seeds shows that it contains $\mathrm{K}$, $\mathrm{Mg}, \mathrm{P}, \mathrm{Ca}, \mathrm{Na}, \mathrm{Fe}, \mathrm{Zn}$ and $\mathrm{Ag}$. Sea buckthorn seed oil and leaves have an efficacy on wound healing area while sea buckthorn have a large spectrum of antiviral, antifungal or antibacterial activities [10]. Pulp of Hippophae rhamnoides L. is not only medicinally used but also utilized in a variety of products such as marmalade and juices [11]. The antibacterial and antifungal activities of sea buckthorn plant extracts may reside in a variety of different components, including phenolic and aldehyde compounds. The root and stem extracts of Hippophae rhamnoides L. express strong antifungal and antibacterial behavior [12]. More than 200 bioactive components, carotenoids, phenolics, lipids, citric acid, flavonoids and above 15 microelements (B, K, F, Al, Mn, Fe etc.) and many vitamins found in Sea buckthorn berries [13]. A number of nutraceutical and pharmacological companies for various products development, attracted to the minerals along with antioxidant attributes of sea buckthorn [14, 15]. To cure various ailments like, lung problems, skin diseases, ulcers, liver disorders, gastro-intestinal problems, sexual dysfunction, malnutrition, jaundice, cancer and chronic hepatitis-B Hippophae rhamnoids $\mathrm{L}$. is used as a remedy $[16,17]$. The presence of many bioactive substances including fatty acids, vitamins, lipids, flavonoids, phenols, tannins and steroids etc. in Hippophae rhamnoides L. plant contributes greatly to its different properties like antifungal, antibacterial, antiinflammatory, immunostimulant, antiradiation, antioxidant, cytoprotective, anticancerous, hepatoprotective,

antiatherosclerosis and wound healing action etc. The present investigation was aimed to examine the antifungal and antibacterial potential of Hippophae rhamnoides L.

\section{Materials and Methods Sample collection Plant material}

Fruits of Hippophae rhamnoides L. (sea buckthorn) were collected from river bank of Warijun, Tehsil Mulkhow, District Chitral, province KPK, Pakistan. The fruits were collected after identification process, the plant was given the voucher no. ICP/000532 and was placed in Department of Botany, Islamia college, Peshawar. Sea buckthorn berries were collected and washed carefully with distilled water to remove the sticking dust particles. The berries were shade dried at room temperature for 21 days and crushed to obtain a fine powder which was preserved in plastic bag for chemical evaluation. 


\section{Microbial samples}

Pure cultures of bacterial (Staphylococcus aureus, Escherichia coli, Pseudomonas aeruginosa, Salmonella typhi, Bacillus subtilis) and Fungal isolates (Rhizopus, Alternaria, Curvulria) were obtained from Microbiology Department, University of Agriculture, Peshawar, Pakistan. Nutrient agar and potato dextrose agar slants were used for preserving bacterial and fungal cultures, respectively.

\section{Extracts preparation}

The powdered material of sea buckthorn berries was soaked in $1000 \mathrm{ml}$ methanol solvent and was kept under shaking for overnight. The mixture was filtered after 24 hours by Whatsman Filter paper No. 1. The same process was repeated three times. Through rotary evaporator, the extracts were concentrated at $50^{\circ} \mathrm{C}$ with $60 \mathrm{rpm}$. The solvent was recollected and extracts was further concentrated through water bath at $50^{\circ} \mathrm{C}$.

\section{Fractionation of crude extracts}

From crude ethanolic extract of Hippophae rhamnoides L. fruit, different fractions (Butanol, chloroform, aqueous and ethyl acetate) were prepared. $8.5 \mathrm{~g}$ of crude ethanolic extract was dissolved in $100 \mathrm{ml}$ of distilled water. The aqueous ethanolic solution was washed with butanol $(350 \mathrm{ml})$, chloroform $(500 \mathrm{ml})$ and ethyl acetate $(350 \mathrm{ml})$. The process was repeated three times. The extracts were then filtered through filter paper, concentrated with rotary evaporator at $50{ }^{\circ} \mathrm{C}$ for chloroform, aqueous, ethyl acetate, butanol while $62^{\circ} \mathrm{C}$ for ethanol extract. To obtain the complete chloroform, aqueous, ethyl acetate, butanol, ethanol extract transfer into different china dishes separately and was place in water bath at a temperature of $50^{\circ} \mathrm{C}$ for three weeks.

\section{Antimicrobial activity}

Antimicrobial potential of various extracted samples of Hippophae rhamnoides L. fruits was conducted by Agar Well Diffusion
Method. Microbial inoculums were prepared by inoculating $20 \mathrm{ml}$ of sterilized nutrient broth which was incubated at $37^{\circ} \mathrm{C}$ for $18-24$ hrs. After incubation, cultured broth was standardization by comparing it with 0.5 McFarland standard. With the help of sterile cotton puff, the bacterial culture on nutrient agar media and fungal culture on potato dextrose agar media plates were thoroughly swabbed. $8 \mathrm{~mm}$ diameter wells were punched in each agar plate by mean of a sterile cork borer. $0.5 \mathrm{~g}$ of each extract were diluted to $1 \mathrm{mg} / 6 \mu \mathrm{l}, \quad 2 \mathrm{mg} / 12 \mu \mathrm{l}$ and $3 \mathrm{mg} / 18 \mu \mathrm{l}$ in dimethyl sulfoxide (DMSO). By using sterile micropipettes, different concentrations of extracts (1mg/well, $2 \mathrm{mg} /$ well and $3 \mathrm{mg} /$ well) were added to the wells. Azithromycin, Ciprofloxacin and Clotrimazole were used as a positive control at a concentration of $1 \mathrm{mg} /$ well against tested microbes. The plates were incubated at $37^{\circ} \mathrm{C}$ for $18-24 \mathrm{hrs}$. After incubation, the diameter of zone of inhibition was observed and measured. From all the three replicates, the reading was taken and the average values were tabularized. With the help of following formula percentage inhibition growth was calculated.

Percentage inhibition of microbial growth $=$ (zone of inhibition of extracts in mm)/ (zone of inhibition of positive control in $\mathrm{mm}) \times$ 100.

\section{Results}

\section{Antibacterial activity Salmonella typhi}

All extracts showed effective growth inhibition of Salmonella typhi. The ethyl acetate and aqueous extracts inhibited bacterial growth with maximum zone of inhibition of about $77.18 \pm 3.05 \%$ and $66.87 \pm 1.15 \%$ at a concentration $3 \mathrm{mg} /$ well. Crude ethyl acetate extract showed zone of inhibition of $60.62 \pm 0.577 \%$ at $2 \mathrm{mg} /$ well while aqueous extracts exhibited $62.5 \pm 1.73 \%$ and $58.43 \pm 0.577 \%$ zone of inhibition in concentration $2 \mathrm{mg} / \mathrm{well}$ and $1 \mathrm{mg} /$ well respectively. Similarly, inhibitory zone of 
ethanol was $59.37 \pm 1 \%$ at $2 \mathrm{mg} /$ well and $66.9 \pm 0.577 \%$ at $3 \mathrm{mg} / \mathrm{well}$ concentrations. Chloroform extracts showed least zone of inhibition at the rate of $28.12 \pm 0 \%$,
$34.37 \pm 1.73 \%$ and $39.68 \pm 2.51 \%$ in concentration of 1,2 and $3 \mathrm{mg} /$ well respectively. The results are summarized in (Fig. 1).

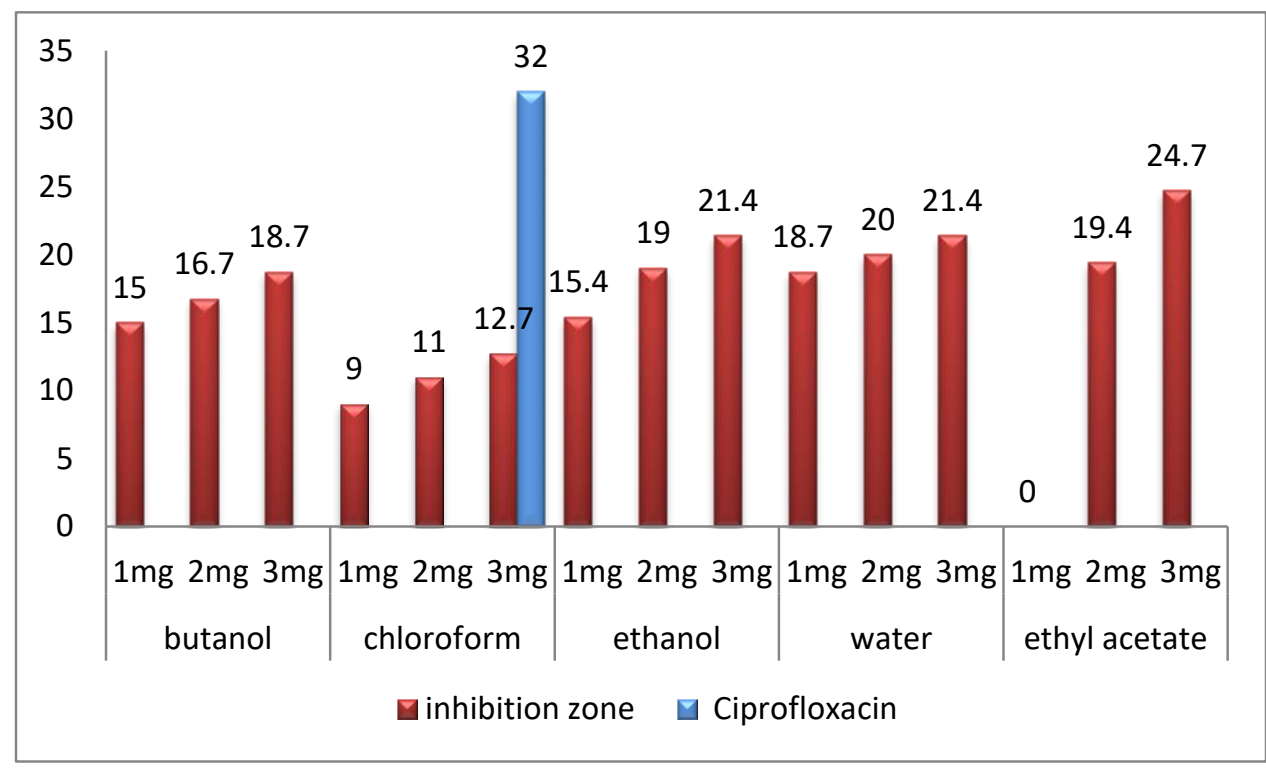

Figure 1. Antibacterial activity of ethyl acetate, chloroform, aqueous, ethanol and butanol extracted sample of Hippophae rhamnoides $\mathrm{L}$. fruit against Salmonella typhi

\section{Escherichia coli}

Data presented in (Fig. 2) indicates the antibacterial activity of different extracted samples of Hippophae rhamnoides L. fruit against Escherichia coli. Among all extracts, aqueous extract possess larger antibacterial potential followed by butanol, chloroform, ethanol and ethyl acetate extracts. The maximum inhibition was indicated for aqueous extract towards $E$. coli were $58.82 \pm 0 \%, 65.88 \pm 1.52 \%$ and $80.58 \pm 0.577 \%$ at $1 \mathrm{mg} /$ well, $2 \mathrm{mg} / \mathrm{well}$ and $3 \mathrm{mg} / \mathrm{well}$ concentrations. Similarly, butanol extract showed $64.70 \pm 2 \%$ activity at $1 \mathrm{mg} /$ well, $66.77 \pm 0.577 \%$ at $2 \mathrm{mg} / \mathrm{well}$ and $66.77 \pm 0.577 \% \quad 3 \mathrm{mg} /$ well concentrations. Correspondingly, the ethanol extracted sample showed $21.47 \pm 0.577 \%$, $42.35 \pm 0.577 \%$ and $69.70 \pm 1.52 \%$ activity at 1,2 and $3 \mathrm{mg} /$ well while chloroform extracted sample showed activity of $20.59 \pm 1.73 \%, \quad 36.47 \pm 0.577 \% \quad$ and
$46.17 \pm 0.577 \%$ in concentrations of $1 \mathrm{mg} /$ well, $2 \mathrm{mg} /$ well and $3 \mathrm{mg} /$ well against the same microbe. The activities are comparable with the reference drug ciprofloxacin applied in concentration of 50 $\mu \mathrm{g} / \mu \mathrm{l}$.

\section{Bacillus subtilis}

The result outlined in (Fig. 3) elaborated that all the fruit extracts of Hippophae rhamnoides L. decreased the growth of pathogenic Bacillus subtilis. The investigation showed that Bacillus subtilis growth was highly suppressed by the extracts. Maximum zone of inhibition $77.41 \pm 1.73 \%$ of ethanolic and $93.54 \pm 3.60 \%$ of aqueous extracted samples obtained against the tested bacteria showed that $3 \mathrm{mg} / \mathrm{well}$ as the effective drug concentration. Ethanol and aqueous solvent extracts also produced a higher percentage of zone of inhibition at 1 and $2 \mathrm{mg} / \mathrm{well}$ i.e. ethanol: $70.96 \pm 1 \%, \quad 70.96 \pm 1 \%$ and aqueous: 
$77.41 \pm 2 \%, 93.54 \pm 0 \%$ as compared to other solvent extracts. Similarly, butanol solvent extract inhibited the growth of same bacteria by $59.35 \pm 0.577 \%, \quad 64.51 \pm 1 \%$ and $65.80 \pm 0.577 \%$ at $1 \mathrm{mg} /$ well, $2 \mathrm{mg} /$ well and $3 \mathrm{mg} /$ well concentrations, even though it showed good inhibitory action than chloroform and ethyl acetate extracts. Chloroform extracted sample offered minimum zone of inhibition of $29.03 \pm 0 \%$ at $1 \mathrm{mg} / \mathrm{well}, 35.48 \pm 0 \%$ at $2 \mathrm{mg} / \mathrm{well}$ and $47.41 \pm 2.88 \%$ at $3 \mathrm{mg} /$ well concentration respectively.

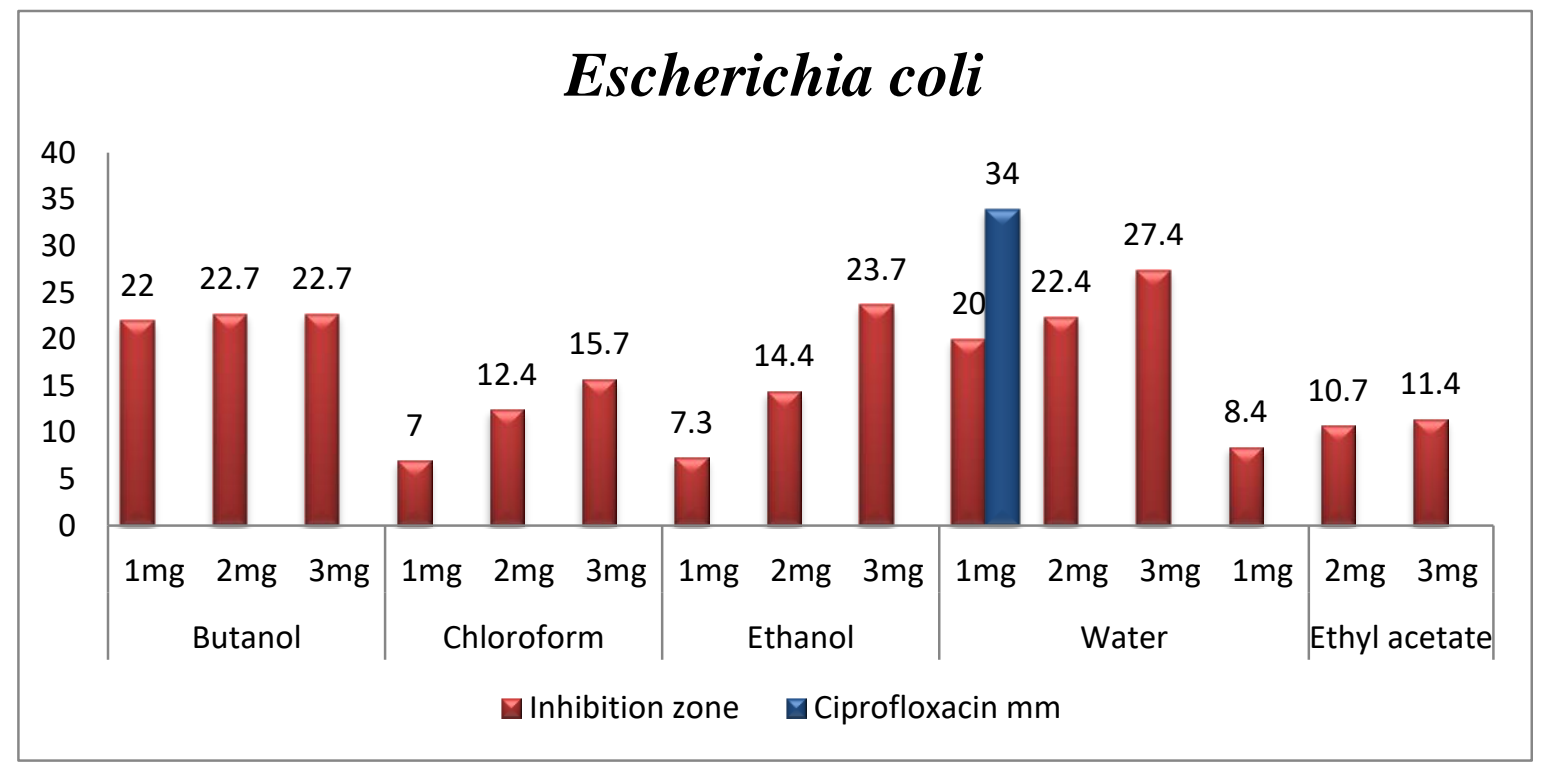

Figure 2. Antibacterial activity of ethyl acetate, chloroform, aqueous, ethanol and butanol extracted sample of Hippophae rhamnoides L. fruit against Escherichia coli

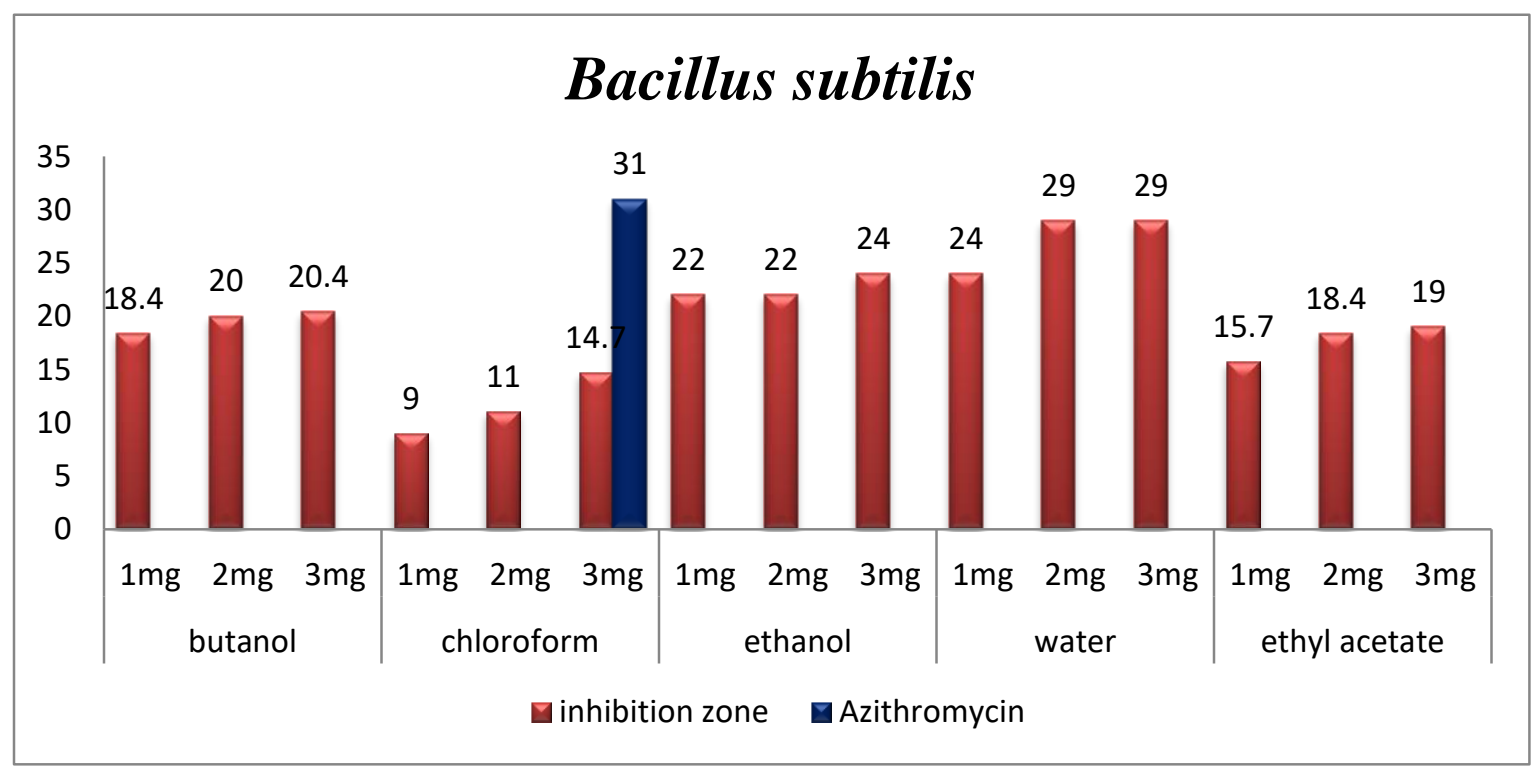

Figure 3. Antibacterial activity of ethyl acetate, chloroform, aqueous, ethanol and butanol extracted sample of Hippophae rhamnoides L. fruit against Bacillus subtilis 


\section{Pseudomonas aeruginosa}

The data shown in (Fig. 4) indicates that different extracted sample of Hippophae rhamnoides $\mathrm{L}$. fruit might contain different inhibitory potential towards Pseudomonas aeruginosa. It was determined from the result that aqueous extract proved itself as good antibacterial agent. It showed higher inhibition $(95.67 \pm 1.15 \%$ at $3 \mathrm{mg} / \mathrm{well})$ of test bacteria. The second highest inhibitory activity was expressed by ethanol extract, which showed $91.34 \pm 2.30 \%$ at a concentration of $3 \mathrm{mg} / \mathrm{well}$. At concentration $2 \mathrm{mg} /$ well, aqueous extract inhibited the growth of Pseudomonas aeruginosa with same zone of inhibition $(95.67 \pm 3.05 \%)$. But at concentration of $1 \mathrm{mg} /$ well it exhibited less inhibition $(69 \pm 0.577 \%)$. Similarly, the buthanol extracted sample showed $56.67 \pm 0 \%, 71.34 \pm 1.15 \%$ and $74.47 \pm 2.08 \%$ activity at 1,2 and $3 \mathrm{mg} / \mathrm{well}$, while least activity was showed by ethyl acetate and chloroform against same bacteria with smallest inhibition zone. Ethyl acetate showed $27.67 \pm 0.577 \%$ at $1 \mathrm{mg} /$ well, $35.67 \pm 1 \%$ at $2 \mathrm{mg} / \mathrm{well}$ and $39 \pm 0.577 \%$ at $3 \mathrm{mg} /$ well. On other the hand chloroform showed $33.34 \pm 0 \%$ at $1 \mathrm{mg} / \mathrm{well}$, $41.34 \pm 0.577 \%$ at $2 \mathrm{mg} /$ well and $46.67 \pm 0 \%$ at
$3 \mathrm{mg} / \mathrm{well}$. All the data were compared with standard drug ciprofloxacin which showed $30 \mathrm{~mm}$ zone of inhibition at $1 \mathrm{mg} / 6 \mu \mathrm{l}$ against the tested bacteria.

\section{Staphylococcus aureus}

Among all extracts, aqueous extract possesses larger antibacterial potential followed by ethanol, chloroform, butanol and ethyl acetate extracts. The maximum inhibition was indicated for aqueous extract towards Staphylococcus aureus were $81 \pm 2.51 \%, \quad 90 \pm 1 \%$ and $97.5 \pm 1 \%$ at $1 \mathrm{mg} /$ well, $\quad 2 \mathrm{mg} /$ well and $3 \mathrm{mg} /$ well concentrations. Similarly, ethanol extract showed $71 \pm 0.577 \%$ activity at $1 \mathrm{mg} /$ well, $83.5 \pm 1.52 \%$ at $2 \mathrm{mg} / \mathrm{well}$ and $88.5 \pm 0.577 \%$ at $3 \mathrm{mg} /$ well concentrations. Correspondingly, the butanol extracted sample showed $36 \pm 0.577 \%, 55 \pm 1 \%$ and $56 \pm 0.577 \%$ activity at 1,2 and $3 \mathrm{mg} /$ well while chloroform extracted sample showed activity of $26.75 \pm 1.15 \%, 57.5 \pm 2 \%$ and $76.67 \pm 12.50 \%$ in concentrations of $1 \mathrm{mg} / \mathrm{well}, 2 \mathrm{mg} / \mathrm{well}$ and $3 \mathrm{mg} /$ well against the same microbe. The activities are comparable with the reference drug Azithromycin applied in concentration of $50 \mu \mathrm{g} / \mu \mathrm{l}$. all the results are summarized in (Fig. 5).

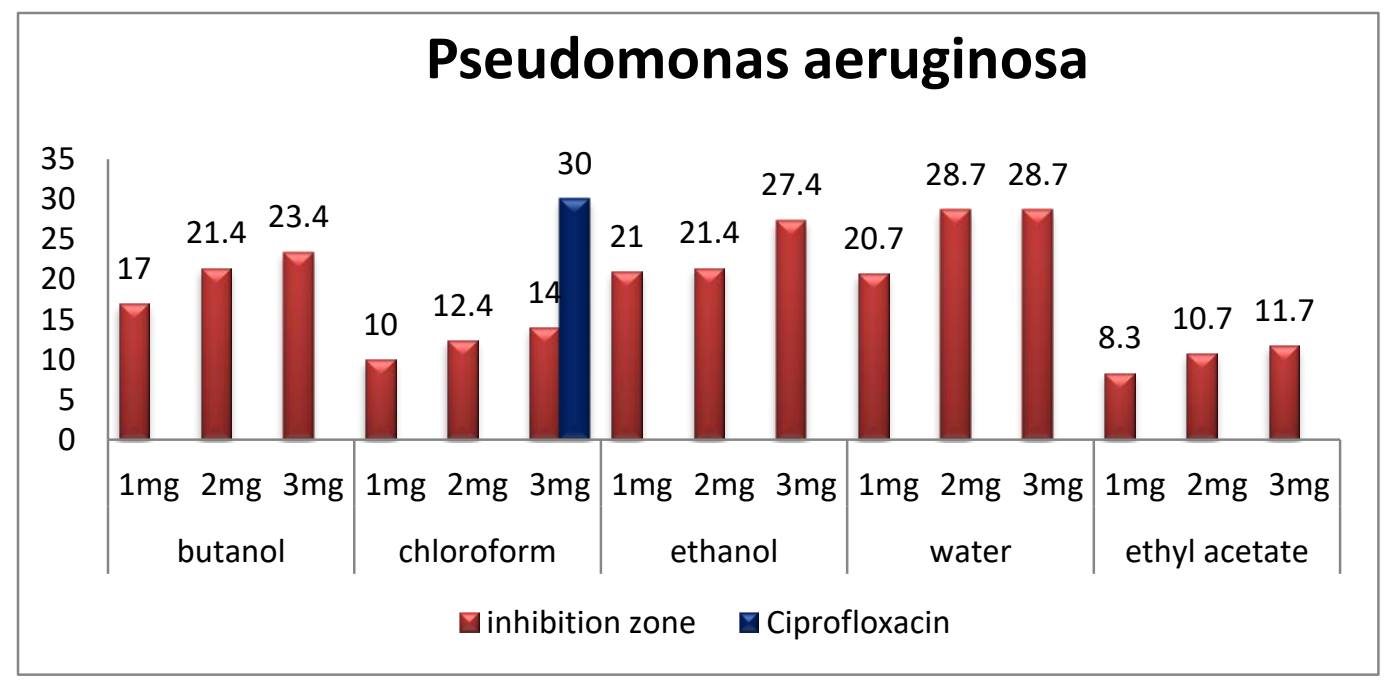

Figure 4. Antibacterial activity of ethyl acetate, chloroform, aqueous, ethanol and butanol extracted sample of Hippophae rhamnoides L. fruit against Pseudomonas aeruginosa 


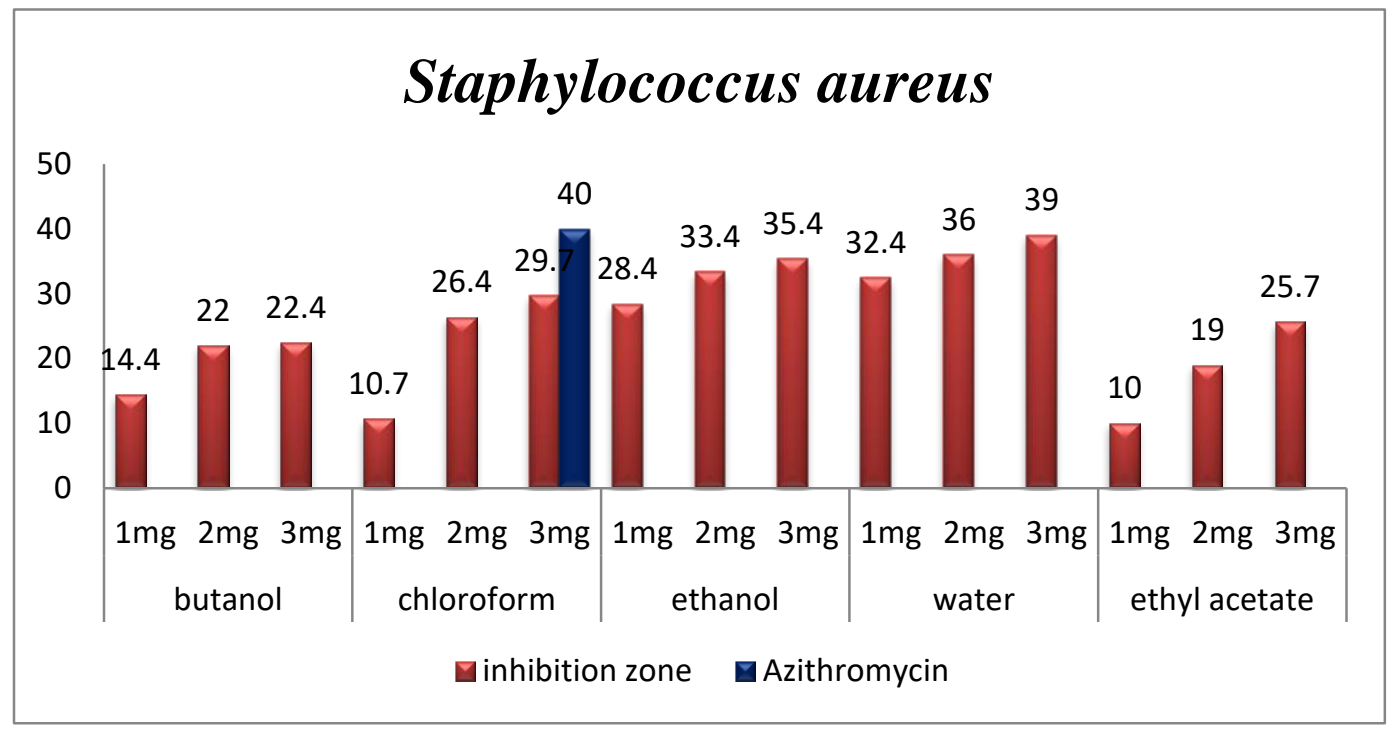

\section{Figure 5. Antibacterial activity of ethyl acetate, chloroform, aqueous, ethanol and extracted sample of Hippophae rhamnoides L. fruit against Staphylococcus aureus}

\section{Antifungal activity \\ Curvulria}

Various extracted samples from Hippophae rhamnoides $\mathrm{L}$. fruit were also screened for their antifungal activity against Curvulria as shown in (Fig. 6). The summarized findings states that the ethanol extracted sample of Hippophae rhamnoides $\mathrm{L}$ shows maximum antifungal activity against the tested microbes with zone of inhibition lying in the range of $92.73 \pm 1 \%$ at $1 \mathrm{mg} / \mathrm{well}$, $93.82 \pm 0.577 \%$ at $2 \mathrm{mg} /$ well and $96.37 \pm 0.577 \%$ at $3 \mathrm{mg} /$ well. The aqueous and butanol extracts of Hippophae rhamnoides $\mathrm{L}$ also showed significant antifungal activity with the zone of inhibition lying in the range of $\quad 75 \pm 1 \%(1 \mathrm{mg} /$ well $)$, $91.46 \pm 1.52 \%(2 \mathrm{mg} /$ well $)$ and $96.98 \pm 1.52 \%$ $(3 \mathrm{mg} /$ well), while in butanol the zone of inhibition lying in the range of $76.92 \pm 5.50 \%$ at $1 \mathrm{mg} /$ well, $76.92 \pm 1.15 \%$ at $2 \mathrm{mg} /$ well and $77.46 \pm 1.52 \%$ at $3 \mathrm{mg} /$ well respectively. Correspondingly, the ethyl acetate extracted sample showed $51.46 \pm 1.52 \%, 52.73 \pm 1.52 \%$ and $55.09 \pm 0.577 \%$ activity at 1,2 and 3 $\mathrm{mg} /$ well while chloroform extracted sample showed activity of $55.09 \pm 4.50 \%, 58.19 \pm 1 \%$ and $66 \pm 5.50 \%$ in concentrations of
$1 \mathrm{mg} /$ well,2mg/well and 3mg/well against the same pathogen. Clotrimazole showed $55 \mathrm{~mm}$ zone of inhibition at $1 \mathrm{mg} /$ well.

\section{Alternaria}

All the extracted sample of Hippophae rhamnoides L. fruit i.e. crude butanol, chloroform, ethanol, water and ethyl acetate were screened against pathogenic fungus Alternaria and results of experiments are summarized in (Fig. 7). The data reveals that aqueous extracted sample had a profound inhibitory effect against Alternaria $s p$. In aqueous extracted sample, maximum growth reduction occurred at higher concentration of $3 \mathrm{mg} /$ well as $96 \pm 0.577 \%$. Ethanol showed lowest inhibition at concentration of $1 \mathrm{mg} /$ well as $44.28 \pm 0.577 \%$. Aqueous extracted sample showed $71.43 \pm 1 \%$ in concentration $2 \mathrm{mg} / \mathrm{well}$ and $56.19 \pm 1.52 \%$ at concentration 1mg/well. The butanol extracted sample exhibited inhibition i.e. $69.76 \pm 0.577 \%, 71.42 \pm 1 \%$ and $80.95 \pm 1 \%$ at the concentration of 1,2 and $3 \mathrm{mg} /$ well respectively. Similarly, chloroform extracted sample showed $75.23 \pm 0.577 \%$, $75.23 \pm 0.577 \%$ and $76.90 \pm 0.577 \%$ at $1 \mathrm{mg} /$ well, $2 \mathrm{mg} /$ well and $3 \mathrm{mg} /$ well concentrations respectively. 
Correspondingly, the ethyl acetate extracted sample showed $67 \pm 0.577 \%, 70.47 \pm 0.577 \%$ and $72.14 \pm 0.577 \%$ activity at 1,2 and 3 $\mathrm{mg} /$ well while ethanol extracted sample showed activity of $61.90 \pm 1 \%$ and
$79.28 \pm 1.52 \%$ in concentrations of $2 \mathrm{mg} /$ well and $3 \mathrm{mg} /$ well against the same microbe. The results were compared with standard drug Clotrimazole.

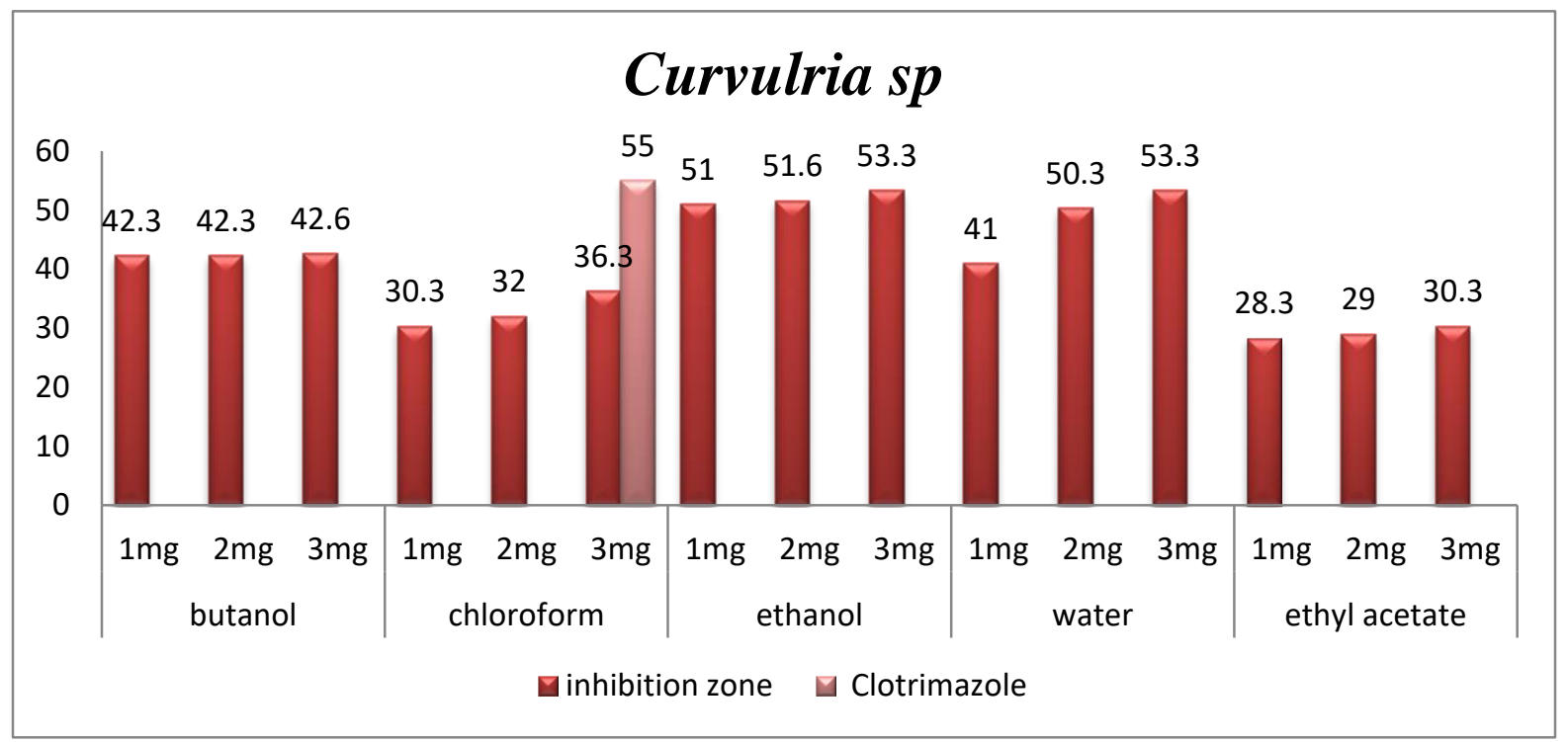

Figure 6. Antifungal activity of ethyl acetate, chloroform, aqueous, ethanol and extracted sample of Hippophae rhamnoides L. fruit against Curvulria sp

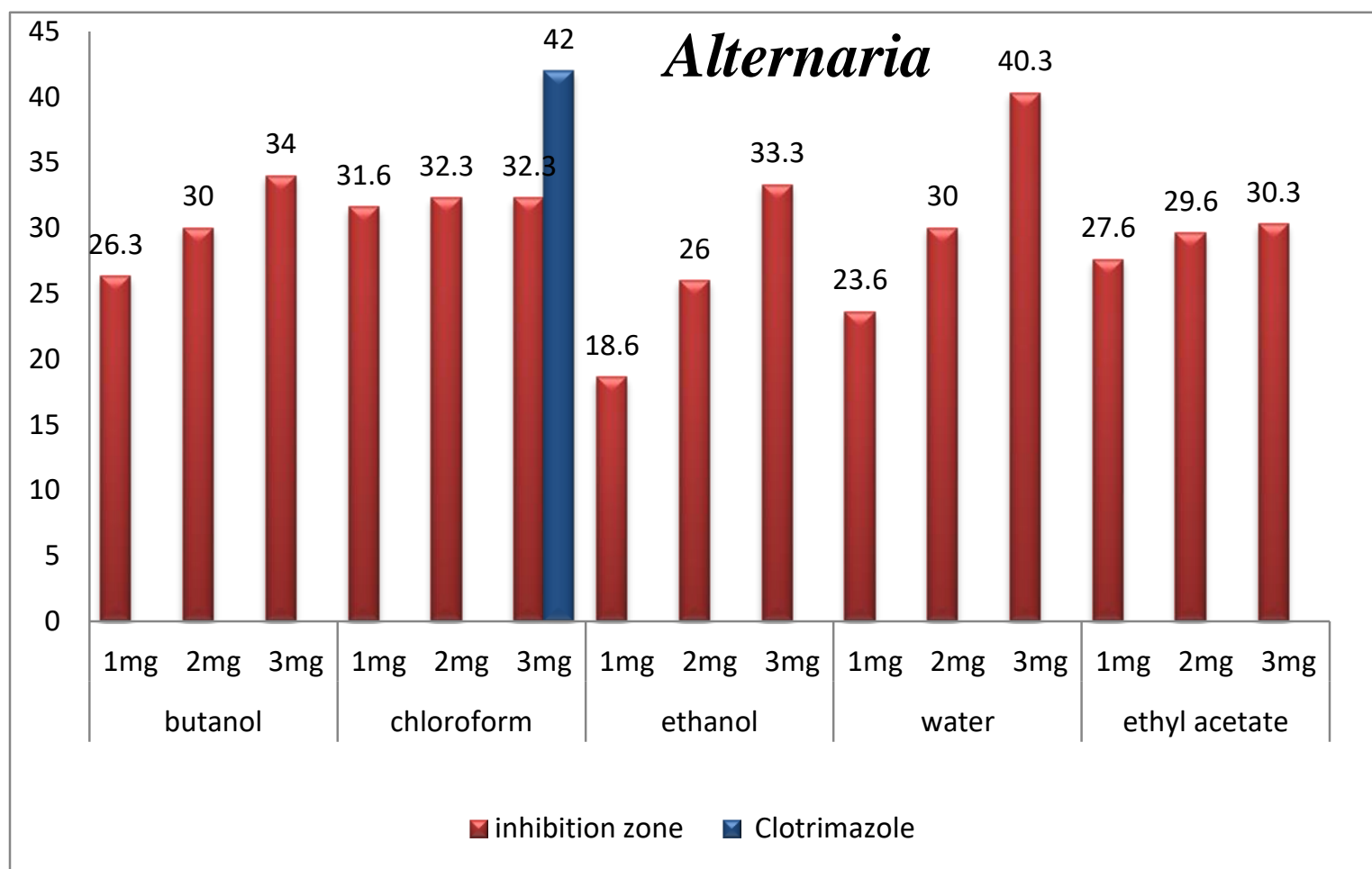

Figure 7. Antifungal activity of ethyl acetate, chloroform, aqueous, ethanol and extracted sample of Hippophae rhamnoides L. fruit against Alternaria 


\section{Rhizopus}

The data presented in (Fig. 8) revealed that the activity of crude butanol, chloroform, ethanolic, aqueous and ethyl acetate extracted samples obtained from fruit of Hippophae rhamnoides L. against Rhizopus. The detail data showed that only the ethanol extracted sample of Hippophae rhamnoides L. fruit showed the best activity against Rhizopus i.e. $53.14 \pm 0.577 \%$ at concentration $1 \mathrm{mg} /$ well, $81 \pm 0.577 \%$ at concentration $2 \mathrm{mg} /$ well and $89 \pm 1 \%$ at concentration $3 \mathrm{mg} /$ well respectfully. The results were compared with standard drug Clotrimazole.

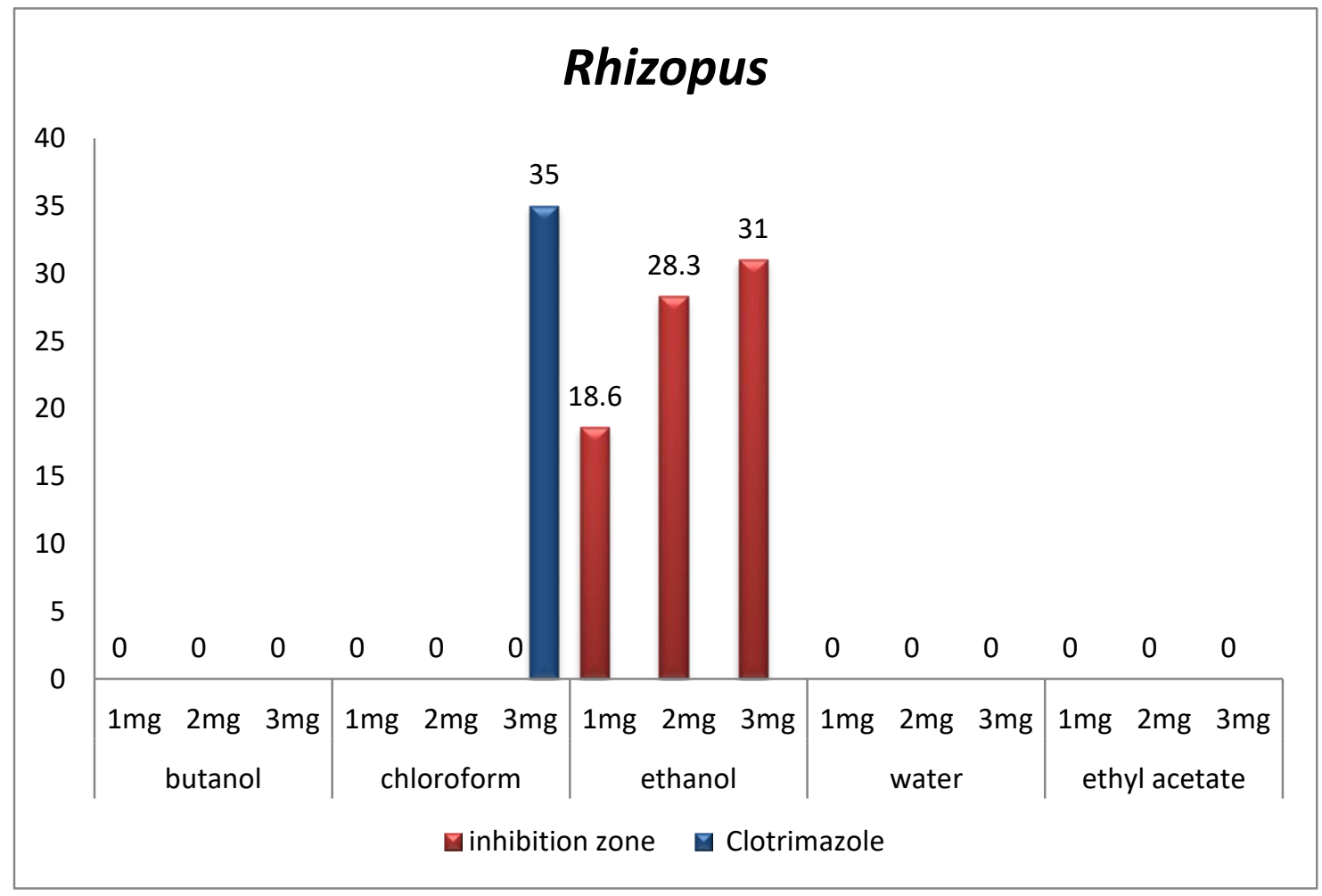

Figure 8. Antifungal activity of ethyl acetate, chloroform, aqueous, ethanol and extracted sample of Hippophae rhamnoides L. fruit against Rhizopus

\section{Discussion}

From decades, microbial infection causes various diseases in insects, plants, humans and spoilage food products, which leads to losses in crop productivity and health problems [10]. The study was aimed to investigate the antimicrobial strength of sea buckthorn, a commonly used traditional medicinal plant around the world. Among the test organisms Salmonella typhi and Curvularia were the most sensitive to the water extract and established highest inhibition as compared to other extracts and showed good control.
In current research work, antibacterial activity of the crude ethanolic as well as aqueous was highest, followed by butanol, chloroform and ethyl acetate extracts respectively. Crude aqueous and ethanolic extracts showed more significant activity against Bacillus subtilis (aqueous: 93.54 $\pm 3.60 \%$, ethanol: $77.41 \pm 1.73 \%$ ), Pseudomonas aeruginosa (aqueous: 95.67 $\pm 1.15 \%$, ethanol: $91.34 \pm 2.30 \%$ ) and Staphylococcus aureus (aqueous: $97.5 \pm 1 \%$, ethanol: $88.5 \pm 0.577 \%$ ) at concentration of $3 \mathrm{mg} /$ well. towards Staphylococcus aureus (chloroform: $\quad 76.67 \pm 12.50 \%$, butanol: 
$56 \pm 0.577 \%$ ), and Pseudomonas aeruginosa (chloroform: $\quad 46.67 \pm 0 \%$, butanol: $74.47 \pm 2.08 \%)$ at concentration of $3 \mathrm{mg} / \mathrm{well}$ dose. Ethyl acetate extract also destroyed all the pathogen with smallest inhibition zones nearly $77.18 \pm 3.05 \%$ in case of Salmonella typhi, $33.52 \pm 0.577 \%$ (E. coli), $61.29 \pm 1 \%$ (Bacillus $\quad$ subtilis), $\quad 39 \pm 0.577 \%$ (Pseudomonas aeruginosa) and $64.25 \pm 14.57 \%$ (Staphylococcus aureus) at $3 \mathrm{mg} /$ well concentration. Similarly, Upadhyay [18] showed the inhibiting growth effects of aqueous and hydro alcoholic leaf extracts of Hippophae rhamnoides $\mathrm{L}$ against Pseudomonas aeruginosa, Bacillus cereus, Staphylococcus aureus and Enterococcus faecalis. According to Gill [19], the methanolic leaf extracts of Hippophae rhamnoides L. showed a good inhibiting effect against some human pathogenic microbes such as Escherichia coli (MTCC 739), Micrococcus luteus (MTCC 2682), Arthrobacter protophormial (MTCC 106) and concluded that methanolic leaf extracts of Hippophae rhamnoides L. was found most effective against Escherichia coli (MTCC 739),which exhibited maximum inhibition zone $(24 \mathrm{~mm})$ at a concentration of $25 \mathrm{mg} / \mathrm{mL}$. In earlier studies, Sea buckthorn berries extracts exhibited the similar trends for inhibition growth observed against bacteria [20]. The phenolic compounds obtained from the berries of sea buckthorn were used for their antibacterial activities and recorded that they were effective against some gram negative bacteria and inhibited their growth but were not effective against the gram positive bacterial strains. Due to the difference between the cell wall composition of gram-positive bacteria and gram-negative bacteria, gram-positive bacteria have been higher sensitivity than gram negative bacteria. As in the outer layer of cell wall of gram positive bacteria contains peptidoglycan, which is not effective permeability barrier. The antifungal potential of all extracted samples of Hippophae rhamnoides $\mathrm{L}$. fruit exerted more significant activities against tested fungi (Curvularia sp., Alternaria sp. and Rhizopus) at different concentrations. The ethanolic extracted sample showed significant activity against Curvularia sp. and Rhizopus sp while moderate activity against Alternaria sp. at all concentration (1, 2 and 3mg/well). Similarly, crude butanol and aqueous extracts showed significant inhibition against Curvularia sp. and Alternaria sp. The chloroform and ethyl acetate extracted sample showed the highest sensitivity of $76.90 \%$ (chloroform) and 72.14\% (ethyl acetate) against Alternaria $s p$. while the inhibition growth towards Curvularia sp. was 66\% (chloroform) and $55.09 \%$ (ethyl acetate) at $3 \mathrm{mg} / \mathrm{well}$. In the case of Rhizopus, no significant activity was observed against all fruit extracts samples except butanol. Lu [21] indicated that concentrated seed extract and crude seed extract of Hippophae rhamnoides L. showed significant antifungal activity against Tilletia and Mucor fungus, while in case of Rhizopus no activity was observed against all test extracts.

\section{Conclusion and Recommendations}

The antimicrobial activities of butanol, ethanol, ethyl acetate, aqueous and chloroform extracts of the sea buckthorn fruit berries matched to Azithromycin (standard antibiotics). These antibiotics give the impression to be wide range in its activities, independent of gram reaction. It is concluded that Hippophae rhamnoides $\mathrm{L}$. fruit contains active constituents, which are helpful against microbial diseases. In order to get better results, more solvent extracts should be applied. Advanced research should be done against different parts of the plant. The study of medicinal plants as antibacterial or antifungal agents is necessary for gaining insight in to the medicinal plants and their real values. A standard method for investigation is essential to use. Similarly, the 
concentration or dilution used must be appropriate. The antimicrobial activities may be due to strong occurrence of active compounds i.e. saponins, tannins, alkaloids, steroids, phenols and flavonoids. However, these medicinal plant species may be subjected to detailed phytochemical and pharmacological studies in order to find out new drugs against pathogenic bacterial and fungal strains.

\section{Authors' contributions}

Conceived and designed the experiments: WM Khan \& A Iqbal, Performed the experiments: Saima, H Shumail, S Khalid \& A Iqbal, Analyzed the data: N Akhtar \& N Ghaffar, Contributed materials/ analysis/ tools: Saima, A Iqbal \& N Akhtar, Wrote the paper: SIU Haq, S Khalid \& WM Khan.

\section{References}

1. Rios J \& Recio M (2005). Medicinal plants and antimicrobial activity. $J$ Ethnopharmacol 100(1-2): 80-84.

2. Dabur R, Gupta A, Mandal T, Singh DD, Bajpai V, Gurav AM \& Lavekar GS (2007). Antimicrobial activity of some Indian medicinal plants. Afr $J$ Tradit Complement Altern Med 4(3): 313-318.

3. Silva N \& Fernandes JA (2010). Biological properties of medicinal plants: a review of their antimicrobial activity. $J$ Venom Anim Toxins incl Trop Dis 16(3): 402-413.

4. Arulmozhi P, Vijayakumar S \& Kumar T (2018). Phytochemical analysis and antimicrobial activity of some medicinal plants against selected pathogenic microorganisms. Microb Pathog 123: 219-226.

5. Kumar R, Kumar GP \& Chaurasia OP (2011). Shashi Bala Singh. Phytochemical and Pharmacological profile of seabuckthorn oil: A Review. Res J Med Plant 1-9.

6. Kagliwal LD, Patil SC, Pol AS, Singhal RS \& Patravale VB (2011). Separation of bioactives from seabuckthorn seeds by supercritical carbon dioxide extraction methodology through solubility parameter approach. Sep Purif Technol 80(3): 533-540.

7. Shah AH, Ahmed D, Sabir M, Arif S, Khaliq I \& Batool F (2007). Biochemical and nutritional evaluations of sea buckthorn (hyppophae rhamnoides L. Spp. Turkestanica) from different locations of Pakistan. Pak J Bot 39(6): 2059-2065.

8. Sabir S, Maqsood H, Ahmed S, Shah A \& Khan M (2005). Chemical and nutritional constituents of sea buckthorn (Hippophae rhamnoides ssp. turkestanica) berries from Pakistan. Ital J Food Sci 17(4): 455.

9. Tigong C, Ni MK, Li R \& Ji F (1991). Investigation of the biological properties of central Asian sea buckthorn growing in the province of Kansu (China). Chem Nat Compd 27(1): 119-121.

10. Gupta S, Gupta A, Ahmed Z \& Kumar A (2011). Antibacterial and antifungal activity in leaf, seed extract and seed oil of seabuckthorn (Hippophae salicifolia D. Don) plant. J Plant Pathol Microbiol 2(2): 1-4.

11. Yang B, Ahotupa M, Määttä $P$ \& Kallio $\mathrm{H}$ (2011). Composition and antioxidative activities of supercritical $\mathrm{CO} 2$-extracted oils from seeds and soft parts of northern berries. Food Res Int 44(7): 2009-2017.

12. Jeong JH, Lee JW, Kim KS, Kim JS, Han SN, Yu CY, Lee JK, Kwon YS \& Kim MJ (2010). Antioxidant and antimicrobial activities of extracts from a medicinal plant, sea buckthorn. J Korean Soc Appl Biol Chem 53(1): 33-38.

13. Rösch D, Bergmann M, Knorr D \& Kroh LW (2003). Structure- antioxidant efficiency relationships of phenolic compounds and their contribution to the antioxidant activity of sea buckthorn juice. J Agric Food Chem 51(15): 42334239. 
14. Raffo A, Paoletti F \& Antonelli M (2004). Changes in sugar, organic acid, flavonol and carotenoid composition during ripening of berries of three seabuckthorn (Hippophae rhamnoides L.) cultivars. Eur Food Res Technol 219(4): 360-368.

15. Tiitinen KM, Yang B, Haraldsson GG, Jonsdottir S \& Kallio HP (2006). Fast analysis of sugars, fruit acids, and vitamin $\mathrm{C}$ in sea buckthorn (Hippophae rhamnoides L.) varieties. J Agric Food Chem 54(7): 2508-2513.

16. Singh K \& Lal B (2008). Ethnomedicines used against four common ailments by the tribal communities of Lahaul-Spiti in western Himalaya. J Ethnopharmacol 115(1): 147-159.

17. Xing J, Yang B, Dong Y, Wang B, Wang J \& Kallio HP (2002). Effects of sea buckthorn (Hippophae rhamnoides L.) seed and pulp oils on experimental models of gastric ulcer in rats. Fitoterapia 73(7-8): 644-650.
18. Upadhyay NK, Kumar MY \& Gupta A (2010). Antioxidant, cytoprotective and antibacterial effects of Sea buckthorn (Hippophae rhamnoides L.) leaves. Food Chem Toxicol 48(12): 3443-3448.

19. Gill N, Sharma R, Arora R \& Bali M (2012). Antioxidant and Antibacterial Activity of Hippophae rhamnoides Methanolic Leaf Extracts from Dry Temperate Agro-climatic Region of Himachal Pradesh. J Plant Sci 7(5): 194.

20. Puupponen-Pimiä R, Nohynek L, Meier C, Kähkönen M, Heinonen M, Hopia A \& Oksman-Caldentey KM (2001). Antimicrobial properties of phenolic compounds from berries. $J$ Appl Microbiol 90(4): 494-507.

21. Lu R (1992). Seabuckthorn-A Multipurpose Plant for Fragile Mountains. International Centre for Integrated Mountain Development (ICIMOD) occasional paper. pp. 20. 